\title{
ANALISIS KINERJA PERAWAT DALAM PENGENDALIAN INFEKSI NOSOKOMIAL DI RSU PKU MUHAMMADIYAH BANTUL YOGYAKARTA
}

\author{
Herpan, Yuniar Wardani \\ Fakultas Kesehatan Masyarakat, Universitas Ahmad Dahlan Yogyakarta
}

\begin{abstract}
Background: Nosocomial infection is an important health care problem worldwide. Nosocomial infections in the hospital at about 9\% (variation 3-21\%) or over 1.4 million patients admitted to hospitals around the world. Nosocomial infections pose some problems, namely an increase in morbidity and mortality, the addition of day care, the increasing cost of care and dissatisfaction with both patients and their families. Nosocomial infection control efforts are very complex and involves a variety of targets including hospital personnel, patients, medical equipment, treatment rooms, and the environment. The purpose of this study was to mengetahuai performance of nosocomial infection control nurse in PKU Muhammadiyah Hospital in Bantul, Yogyakarta.
\end{abstract}

Methods: This study was a type of observational analytic study using quantitative cross- sectional survey design. The sample size was of the study was 50 nurses. The sampling technique used Sampling Random sampling techniques with systematic sampling. Data was taken using a questionnaire.

Results: Based on the results of the bivariate test there were three variables that were statistically significant, namely knowledge ( $p$ value $=0.000$ and $R P=7.115$ ), attitude ( $p$ value $=0.000$ and RP $=6.519)$ and skills $(p$ value $=0.000$ and $R P=6.519)$. Non- significant variables: education $(p$ value $=0.486$ and $R P=0.542)$ and training $(p$ value $=0.670$ and $R P=1.432)$.

Conclusion: There was a statistically significant relationship between knowledge, attitudes and skills in nosocomial infection control and there was no statistically significant relationship between education and training in nosocomial infection control.

Key words: nosocomial infection control, nurse performance, cross sectional.

\section{PENDAHULUAN}

Kesehatan merupakan hak asasi manusia dan salah satu unsur kesejahteraan yang harus diwujudkan sesuai dengan cita-cita bangsa Indone Di dalam Undang-undang Nomor 36 Tahun 2009 tentang Kesehatan, pada pasal 2 dan 3 dinyatakan bahwa pembangunan kesehatan diselenggarakan dengan berazaskan perikemanusiaan, keseimbangan, manfaat, perlindungan, penghormatan terhadap hak dan kewajiban, keadilan, gender dan nondiskriminatif dan norma-norma agama. ${ }^{1}$

Infeksi nosokomial (INOS) merupakan masalah perawatan kesehatan yang penting diseluruh dunia. Terjadinya infeksi nosokomial menimbulkan beberapa masalah, yaitu peningkatan angka kesakitan dan kematian, penambahan hari perawatan, peningkatan biaya perawatan dan ketidakpuasan baik pasien maupun keluarganya. ${ }^{2}$ 
Di Indonesia Infeksi merupakan salah satu penyebab utama kematian ibu dan bayi baru lahir. Infeksi ini masih merupakan salah satu penyebab utama kematian dan kesakitan di rumah sakit dan fasilitas pelayanan kesehatan lainnya, selain itu menyebabkan perpanjangan masa rawat inap bagi penderita. Infeksi nosokomial di rumah sakit mencapai $9 \%$ (variasi $3-21 \%$ ) atau lebih 1,4 juta pasien rawat inap di rumah sakit seluruh dunia. ${ }^{3}$

Rumah Sakit Umum PKU Muhammadiyah Bantul adalah rumah sakit tipe C dengan fasilitas yang cukup lengkap. Rumah sakit ini telah menetapkan sistem jaminan mutu ISO 9001:2000. Harapan dengan pemberlakuan ISO 9001:2000 dapat meningkatkan pelayanan kesehatan seiring dengan peningkatan kebutuhan masyarakat akan pelayanan kesehatan dan profesionalisme pemberi pelayanan kesehatan. Harapan diberlakukannya sistem manajemen mutu seharusnya pemberi pelayanan kesehatan merasa ikut memiliki atau bertanggung jawab atas keberadaan rumah sakit baik secara organisasi keseluruhan maupun di tingkat unit khususnya dalam usaha dalam pencegahan INOS. ${ }^{4}$

\section{METODE PENELITIAN}

Penelitian ini menggunakan rancangan observasional analitik kuantitatif dengan menggunakan rancangan survei cross sectional. Survei cross sectional adalah suatu penelitian untuk mempelajari dinamika korelasi antara faktor-faktor dengan efek, dengan cara pendekatan, observasi atau pengumpulan data sekaligus pada suatu saat (point time approach). Artinya, tiap subjek penelitian hanya di observasi sekali saja dan pengukuran dilakukan terhadap suatu karakter atau variabel subjek pada saat pemeriksaan. Hal ini tidak berarti bahwa semua subjek penelitian diamati pada waktu yang sama.

Sampel penelitian ini adalah perawat tetap yang bekerja di RSU PKU Muhammadiyah Bantul Yogyakarta. Pengambilan sampel digunakan metode Random Sampling yaitu dengan pencuplikan systematic sampling. Yaitu teknik pengambilan sampel berdasarkan urutan dari anggota populasi yang telah diberi nomor urut. Besar sampel setelah dihitung sebesar 50 sampel dari 100 responden.

Subyek penelitian adalah yang memenuhi kriteria inklusi.

a. Kriteria inklusi perawat tetap yang bekerja di RSU PKU Muhammadiyah Bantul Yogyakarta.

b. Kriteria eksklusi perawat yang sedang studi lanjut atau cuti

Penelitian ini menggunakan instrumen penelitian berupa kuesioner untuk mengumpulkan data mengenai pendidikan, pelatihan, pengetahuan, sikap dan keterampilan responden. Data dianalisis secara univariat, bivariat dan multivariat. Analisis univariat yang bertujuan menjelaskan atau mendeskripsikan karakteristik setiap variabel penelitian. Analisis bivariat adalah analisis yang melibatkan sebuah variabel dependen dan sebuah variabel independen. Analisis bivariat dapat dilihat ada tidaknya perbedaan atau kemaknaan secara statistik ditunjukkan dari hasil perhitungan table silang $2 \times 2$. Tingkat kepercayaan yang digunakan $95 \%$ dan $P<0,05$, artinya hipotesis akan diterima jika $P<0,05$ dan atau Confidence Interval $(\mathrm{Cl})$ tidak mencakup angka satu. Analisis multivariat adalah analisis yang bertujuan untuk mengetahui 
hubungan lebih dari satu variabel independent dengan satu variabel dependent.

\section{HASIL PENELITIAN DAN PEMBAHASAN}

\section{A. Hasil Penelitian}

\section{1) Karakteristik Responden}

Jumlah responden dalam penelitian ini sebanyak 50 responden. Rincian karakteristik responden dalam penelitian ini sebagai berikut:

\section{a) Jenis Kelamin Responden}

Berdasarkan hasil penelitian dari 50 responden, dapat diketahui sebagian besar responden perempuan sebanyak $37(74 \%)$ dari 50 responden dari pada jumlah responden laki-laki yaitu $13(26 \%)$ dari 50 responden. Distribusi responden menurut kelompok jenis kelamin dapat dilihat sebagai berikut:

Tabel 1. Distribusi Frekuensi Jenis Kelamin Responden di RSU PKU Muhammadiyah Bantul tahun 2012

\begin{tabular}{ccc}
\hline Jenis Kelamin & Jumlah (perawat) & Persentase (\%) \\
\hline Perempuan & 37 & 74 \\
\hline Laki-laki & 13 & 26 \\
\hline Total & 50 & 100 \\
\hline
\end{tabular}

Sumber: Data primer peneliti

\section{b) Usia Responden}

Distribusi responden menurut kelompok usia responden dalam penelitian dapat dilihat Tabel 2 sebagai berikut:

Tabel 2. Distribusi Frekuensi Kelompok Usia Responden di RSU PKU Muhammadiyah Bantul Yogyakarta tahun 2012

\begin{tabular}{ccc}
\hline Umur (tahun) & Jumlah (perawat) & Persentase (\%) \\
\hline $20-25$ & 1 & 2 \\
\hline $26-30$ & 18 & 36 \\
\hline $31-35$ & 27 & 54 \\
\hline $36-40$ & 4 & 8 \\
\hline Total & 50 & 100 \\
\hline
\end{tabular}

Sumber: Data primer peneliti 
Berdasarkan Tabel 2 diatas dapat diketahui sebagian besar responden berumur 31-35 tahun, yaitu 27 orang (54\%).

\section{c) Lama bekerja responden}

Distribusi lama bekerja responden dalam penelitian dapat dilihat pada Tabel 3 sebagai berikut:

Tabel 3. Distribusi frekuensi lama bekerja responden di RSU PKU Muhammadiyah Bantul Yogyakarta tahun 2012

\begin{tabular}{ccc}
\hline Lama bekerja & Jumlah (perawat) & Persentase (\%) \\
\hline$<1$ Tahun & - & - \\
\hline$>1$ Tahun & 11 & 22 \\
\hline$>5$ Tahun & 39 & 78 \\
\hline Total & 50 & 100 \\
\hline
\end{tabular}

Sumber: Data primer peneliti

\section{2) Analisis Univariat}

Analisis univariat dilakukan untuk mendapatkan gambaran umum dengan cara mendiskripsikan tiap-tiap variabel yang dijadikan objek penelitian. Gambaran variabel penelitian tersebut dilihat dalam bentuk tabel distribusi frekuensi. Hasil analisis univariat dalam penelitian ini dapat dilihat pada tabel-tabel dibawah ini.

\section{a) Pendidikan Responden}

Distribusi frekuensi pendidikan responden tentang kinerja perawat dapat dilihat pada tabel berikut:

Tabel 4. Distribusi Tingkat Pendidikan Responden Tentang Kinerja Perawat Dalam Pengendalian INOS di RSU PKU Muhammadiyah Bantul Yogyakarta 2012

\begin{tabular}{ccc}
\hline Pendidikan perawat & Jumlah & Persentase (\%) \\
\hline D III & 48 & 96 \\
\hline S 1 & 2 & 4 \\
\hline Total & 50 & 100 \\
\hline
\end{tabular}

Sumber: Data primer peneliti

Berdasarkan Tabel 4, menunjukkan bahwa sebagian besar responden berpendidikan DIII sebanyak 48 orang (96\%). 


\section{b) Pelatihan Responden Tentang INOS}

Distribusi pelatihan responden tentang Infeksi Nosokomial (INOS) dapat dilihat pada tabel berikut:

Tabel 5. Distribusi Pelatihan Responden Tentang INOS Di RSU PKU Muhammadiyah Bantul Yogyakarta 2012

\begin{tabular}{ccc}
\hline Pelatihan Perawat & Jumlah & Persentase (\%) \\
\hline Tidak Pernah & 8 & 16 \\
\hline Pernah & 42 & 84 \\
\hline Total & 50 & 100 \\
\hline
\end{tabular}

Sumber: Data primer peneliti

Berdasarkan Tabel 5, menunjukkan bahwa sebagian besar responden pernah mengikuti pelatihan INOS sebanyak 42 orang (84\%).

\section{c) Pengetahuan Responden Tentang Pencegahan INOS}

Distribusi pengetahuan responden tentang Infeksi Nosokomial (INOS) dapat dilihat pada tabel berikut.

Tabel 6. Distribusi Pengetahuan Responden Tentang INOS Di RSU PKU Muhammadiyah Bantul Yogyakarta 2012

\begin{tabular}{ccc}
\hline Pengetahuan INOS & Jumlah & Persentase (\%) \\
\hline Rendah & 13 & 26 \\
\hline Tinggi & 37 & 74 \\
\hline Total & 50 & 100 \\
\hline
\end{tabular}

Sumber: Data primer peneliti

Berdasarkan Tabel 6, menunjukkan bahwa sebagian besar responden berpengetahuan tinggi sebanyak 37 orang $(74 \%)$. 
d) Sikap Responden Tentang Pencegahan INOS

Distribusi sikap responden tentang Infeksi Nosokomial (INOS) dapat dilihat pada tabel berikut.

Tabel 7. Distribusi Sikap Responden Tentang INOS Di RSU PKU Muhammadiyah Bantul Yogyakarta 2012

\begin{tabular}{ccc}
\hline Sikap Responden & Jumlah & Persentase (\%) \\
\hline Negatif & 18 & 36 \\
\hline Positif & 32 & 64 \\
\hline Total & 50 & 100 \\
\hline
\end{tabular}

Sumber: Data primer peneliti

Berdasarkan Tabel 7, menunjukkan bahwa sebagian besar responden memiliki sikap positif sebanyak 32 orang (64\%).

\section{e) Keterampilan Responden Tentang Pencegahan INOS}

Distribusi keterampilan responden tentang Infeksi Nosokomial (INOS) dapat dilihat pada tabel berikut.

Tabel 8. Distribusi keterampilan Responden Tentang INOS di RSU PKU Muhammadiyah Bantul Yogyakarta 2012

\begin{tabular}{ccc}
\hline Keterampilan tentang INOS & Jumlah & Persentase (\%) \\
\hline Tidak Baik & 18 & 36 \\
\hline Baik & 32 & 64 \\
\hline Total & 50 & 100 \\
\hline
\end{tabular}

Sumber: Data primer peneliti

Berdasarkan Tabel 8, menunjukkan bahwa sebagian besar responden memiliki keterampilan baik sebanyak 32 orang (64\%). 


\section{f) Kinerja Perawat Dalam Pengendalian INOS}

Distribusi kinerja perawat dalam pengendalian INOS dapat dilihat pada tabel berikut.

Tabel 9. Distribusi Hasil Nilai Kinerja Perawat Dalam Pengendalian INOS di RSU PKU Muhammadiyah Bantul Yogyakarta 2012

\begin{tabular}{ccc}
\hline Kinerja Perawat & Jumlah & Persentase (\%) \\
\hline Tidak Baik & 14 & 28 \\
\hline Baik & 36 & 72 \\
\hline Total & 50 & 100 \\
\hline
\end{tabular}

Sumber: Data primer peneliti

Berdasarkan Tabel 9, menunjukkan bahwa sebagian besar responden yang memiliki kinerja baik sebanyak 36 oarang $(72 \%)$.

\section{3) Analisis Bivariat}

Analisis bivariat adalah analisis yang dilakukan dengan menggunakan tabulasi silang yang bertujuan untuk melihat hubungan variabel bebas (independent) dengan variabel terikat (dependent) berdasarkan distribusi sel-sel yang ada.

a. Hubungan Antara Pendidikan Dengan Kinerja Perawat Dalam Pengendalian INOS

Tabel 10. Hubungan Pendidikan Dengan Kinerja Perawat Dalam Pengendalian INOS di RSU PKU Muhammadiyah Bantul Yogyakarta 2012

\begin{tabular}{|c|c|c|c|c|c|c|c|c|c|}
\hline \multirow{3}{*}{$\begin{array}{l}\text { Pendidi- } \\
\text { kan } \\
\text { Respon- } \\
\text { den }\end{array}$} & \multicolumn{4}{|c|}{ Kinerja perawat } & \multirow{2}{*}{\multicolumn{2}{|c|}{ Total }} & \multirow{3}{*}{$\begin{array}{c}P \\
\text { value }\end{array}$} & \multirow{3}{*}{$\mathrm{Cl}$} & \multirow{3}{*}{$R P$} \\
\hline & \multicolumn{2}{|c|}{ Tidak Baik } & \multicolumn{2}{|c|}{ Baik } & & & & & \\
\hline & $\mathrm{N}$ & $\%$ & $\mathrm{~N}$ & $\%$ & $n$ & $\%$ & & & \\
\hline D III & 13 & 13 & 35 & 35 & 48 & 48 & & & \\
\hline S 1 & 1 & 1 & 1 & 1 & 2 & 2 & 0,486 & $\begin{array}{l}(0,126- \\
2336)\end{array}$ & 0,542 \\
\hline Total & 14 & 14 & 36 & 36 & 50 & 50 & & & \\
\hline
\end{tabular}

Sumber: Data primer peneliti 
Hasil analisis bivariat hubungan antara pendidikan dengan kinerja perawat dalam pengendalian INOS dengan $\alpha=0,05$ ini didapat $p$ value $=$ 0,486 dan $R P=0,542(95 \% C l 0,126-2,336)$. Hasil analisis secara statistik 0,486>0,05 dan $\mathrm{Cl}$ mencakup angka satu, yang berarti hubungan antara pendidikan dengan kinerja perawat dalam pengendalian INOS tidak bermakna, atau tidak ada hubungan antara pendidikan dengan kinerja perawat dalam pengendalian INOS. Hasil analisis secara biologis berdasarkan nilai $R P$, bahwa perawat dengan tingkat pendidikan $D$ III berpeluang untuk tidak mengendalikan INOS sebesar 0,542 kali.

b. Hubungan Antara Pelatihan Dengan Kinerja Perawat Dalam Pengendalian INOS Untuk mengetahui Hubungan antara pelatihan dengan kinerja perawat dalam pengendalian INOS, dapat dilihat pada tabel 11 sebagai berikut:

Tabel 11. Hubungan Pelatihan Dengan Kinerja Perawat Dalam Pengendalian INOS di RSU PKU Muhammadiyah Bantul Yogyakarta 2012

\begin{tabular}{|c|c|c|c|c|c|c|c|c|c|}
\hline \multirow{3}{*}{$\begin{array}{l}\text { Pelatihan } \\
\text { Responden }\end{array}$} & \multicolumn{4}{|c|}{ Kinerja perawat } & \multirow{2}{*}{\multicolumn{2}{|c|}{ Total }} & \multirow{3}{*}{$\begin{array}{c}P \\
\text { value }\end{array}$} & \multirow{3}{*}{$\mathrm{Cl}$} & \multirow{3}{*}{$R P$} \\
\hline & \multicolumn{2}{|c|}{ Tidak Baik } & \multicolumn{2}{|c|}{ Baik } & & & & & \\
\hline & $\mathrm{N}$ & $\%$ & $\mathrm{~N}$ & $\%$ & $\mathrm{~N}$ & $\%$ & & & \\
\hline $\begin{array}{c}\text { Tidak } \\
\text { Pernah }\end{array}$ & 3 & 3 & 5 & 5 & 8 & 8 & & 1,432 & \\
\hline Pernah & 11 & 11 & 31 & 31 & 42 & 42 & 0,670 & $\begin{array}{c}(0,512- \\
4005)\end{array}$ & 1,432 \\
\hline Total & 14 & 14 & 36 & 36 & 50 & 50 & & & \\
\hline
\end{tabular}

Sumber: Data primer peneliti

Hasil analisis bivariat hubungan antara pelatihan dengan kinerja perawat dalam pengendalian INOS dengan $\alpha=0,05$ ini didapat $p$ value $=$ 0,670 dan $R P=1,432(95 \% C l 0,512-4,005)$. Hasil analisis secara statistik $0,670>0,05$ dan $\mathrm{Cl}$ mencakup angka satu, yang berarti hubungan antara pelatihan dengan kinerja perawat dalam pengendalian INOS tidak bermakna, atau tidak ada hubungan antara pelatihan dengan kinerja perawat dalam pengendalian INOS. Hasil analisis secara biologis berdasarkan nilai $R P$, bahwa perawat yang tidak memiliki pelatihan INOS berpeluang untuk tidak mengendalikan INOS sebesar 1,432 kali. 
c. Hubungan Antara Pengetahuan Dengan Kinerja Perawat Dalam Pengendalian INOS

Tabel 12.Hubungan Pengetahuan Dengan Kinerja Perawat Dalam Pengendalian INOS di RSU PKU Muhammadiyah Bantul Yogyakarta 2012

\begin{tabular}{|c|c|c|c|c|c|c|c|c|c|}
\hline \multirow{3}{*}{$\begin{array}{c}\text { Pengetahuan } \\
\text { Responden }\end{array}$} & \multicolumn{4}{|c|}{ Kinerja perawat } & \multirow{2}{*}{\multicolumn{2}{|c|}{ Total }} & \multirow{3}{*}{$\begin{array}{c}P \\
\text { value }\end{array}$} & \multirow{3}{*}{$\mathrm{Cl}$} & \multirow{3}{*}{$R P$} \\
\hline & \multicolumn{2}{|c|}{ Tidak Baik } & \multicolumn{2}{|c|}{ Baik } & & & & & \\
\hline & $\mathrm{n}$ & $\%$ & $\mathrm{~N}$ & $\%$ & $\mathrm{n}$ & $\%$ & & & \\
\hline Rendah & 10 & 10 & 3 & 3 & 13 & 13 & & 7115 & \\
\hline Tinggi & 4 & 4 & 33 & 33 & 37 & 37 & 0,000 & $(2,691-$ & 7.115 \\
\hline Total & 14 & 14 & 36 & 36 & 50 & 50 & & $18,812)$ & \\
\hline
\end{tabular}

Sumber: Data primer peneliti

Hasil analisis bivariat hubungan antara pengetahuan dengan kinerja perawat dalam pengendalian INOS dengan $\alpha=0,05$ ini didapat $p$ value $=$ 0,000 dan $R P=7,115(95 \% C l$ 2,691-18,812). Hasil analisis secara statistik $0,000<0,05$ dan $\mathrm{Cl}$ tidak mencakup angka satu, yang berarti hubungan antara pengetahuan dengan kinerja perawat dalam pengendalian INOS bermakna, atau ada hubungan antara pengetahuan dengan kinerja perawat dalam pengendalian INOS. Hasil analisis secara biologis berdasarkan nilai $R P$, bahwa perawat dengan tingkat pengetahuan rendah berpeluang untuk tidak mengendalikan INOS sebesar 7,115 kali.

d. Hubungan Antara Sikap Dengan Kinerja Perawat Dalam Pengendalian INOS

Tabel 13.Hubungan Sikap Dengan Kinerja Perawat Dalam Pengendalian INOS di RSU PKU Muhammadiyah Bantul Yogyakarta 2012

\begin{tabular}{|c|c|c|c|c|c|c|c|c|c|}
\hline \multirow{3}{*}{$\begin{array}{c}\text { Sikap } \\
\text { Responden }\end{array}$} & \multicolumn{4}{|c|}{ Kinerja perawat } & \multirow{2}{*}{\multicolumn{2}{|c|}{ Total }} & \multirow{3}{*}{$\begin{array}{c}P \\
\text { value }\end{array}$} & \multirow{3}{*}{$\mathrm{Cl}$} & \multirow{3}{*}{$R P$} \\
\hline & \multicolumn{2}{|c|}{ Tidak Baik } & \multicolumn{2}{|c|}{ Baik } & & & & & \\
\hline & $\mathrm{N}$ & $\%$ & $\mathrm{~N}$ & $\%$ & $n$ & $\%$ & & & \\
\hline Negatif & 11 & 11 & 7 & 7 & 18 & 18 & & 6.519 & \\
\hline Positif & 3 & 3 & 29 & 29 & 32 & 32 & 0,000 & $(2,088-$ & 6,519 \\
\hline Total & 14 & 14 & 36 & 36 & 50 & 50 & & & \\
\hline
\end{tabular}

Sumber: Data primer peneliti 
Hasil analisis bivariat hubungan antara sikap dengan kinerja perawat dalam pengendalian INOS dengan $\alpha=0,05$ ini didapat $p$ value $=0,000$ dan $R P=6,519 \quad(95 \%$ Cl 2,088-20,352). Hasil analisis secara statistik $0,000<0,05$ dan $\mathrm{Cl}$ tidak mencangkup angka satu, yang berarti hubungan antara sikap dengan kinerja perawat dalam pengendalian INOS bermakna, atau ada hubungan antara sikap dengan kinerja perawat dalam pengendalian INOS. Hasil analisis secara biologis berdasarkan nilai $R P$, bahwa perawat yang memiliki sikap negatif berpeluang untuk tidak mengendalikan INOS sebesar 6,519 kali.

e. Hubungan Antara Keterampilan Dengan Kinerja Perawat Dalam Pengendalian INOS

Tabel 14. Hubungan Keterampilan Dengan Kinerja Perawat Dalam Pengendalian INOS di RSU PKU Muhammadiyah Bantul Yogyakarta 2012

\begin{tabular}{|c|c|c|c|c|c|c|c|c|c|}
\hline \multirow{3}{*}{$\begin{array}{l}\text { Keterampilan } \\
\text { Responden }\end{array}$} & \multicolumn{4}{|c|}{ Kinerja perawat } & \multirow{2}{*}{\multicolumn{2}{|c|}{ Total }} & \multirow{3}{*}{$\begin{array}{l}P \\
\text { value }\end{array}$} & \multirow{3}{*}{$\mathrm{Cl}$} & \multirow{3}{*}{$R P$} \\
\hline & \multicolumn{2}{|c|}{ Tidak Baik } & \multicolumn{2}{|c|}{ Baik } & & & & & \\
\hline & $\mathrm{n}$ & $\%$ & $\mathrm{~N}$ & $\%$ & $\mathrm{~N}$ & $\%$ & & & \\
\hline Tidak Baik & 11 & 11 & 7 & 07 & 18 & 18 & \multirow{3}{*}{0,000} & \multirow{3}{*}{$\begin{array}{c}6,519 \\
(2,088- \\
20,352)\end{array}$} & \multirow{3}{*}{6,519} \\
\hline Baik & 3 & 3 & 29 & 29 & 32 & 32 & & & \\
\hline Total & 14 & 14 & 36 & 36 & 50 & 50 & & & \\
\hline
\end{tabular}

Sumber: Data primer peneliti

Hasil analisis bivariat hubungan antara keterampilan dengan kinerja perawat dalam pengendalian INOS dengan $\alpha=0,05$ ini didapat $p$ value $=$ 0,000 dan $R P=6,519(95 \% C l$ 2,088-20,352). Hasil analisis secara statistik $0,000<0,05$ dan $\mathrm{Cl}$ tidak mencangkup angka satu, yang berarti hubungan antara keterampilan dengan kinerja perawat dalam pengendalian INOS bermakna, atau ada hubungan antara keterampilan dengan kinerja perawat dalam pengendalian INOS. Hasil analisis secara biologis berdasarkan nilai $R P$, bahwa perawat yang memiliki keterampilan tidak baik berpeluang untuk tidak mengendalikan INOS sebesar 6,519 kali.

\section{4) Analisis Multivariat}

Analisis multivariat adalah analisis yang bertujuan untuk mengetahui hubungan lebih dari satu variabel independent dengan satu variabel dependent. Analisis multivariat dilakukan untuk menentukan variabel mana yang menjadi faktor paling dominan atau paling berpengaruh. 
Tabel 15. Hasil Analisis Multiple Logistic Regression Penentu Kinerja Perawat Dalam Pengendalian INOS di RSU PKU Muhammadiyah Bantul Yogyakarta tahun 2012

\begin{tabular}{cccccc}
\hline \multirow{2}{*}{ Varibel } & \multirow{2}{*}{ B } & \multirow{2}{*}{ Sig } & \multirow{2}{*}{ Exp (B) } & \multicolumn{2}{c}{ 95\% Cl EXP B } \\
\cline { 5 - 6 } & & & & Lower & Upper \\
\hline Sikap & 2,721 & 0,000 & 15,190 & 3,322 & 69,467 \\
\hline Keterampilan & 2,721 & 0,000 & 15,190 & 3,322 & 69,467 \\
\hline Pengetahuan & 3,314 & 0,000 & 27,500 & 5,251 & 144,013 \\
\hline
\end{tabular}

Sumber: Data primer peneliti

Penjelasan Tabel 15 menunjukkan bahwa ada hubungan yang bermakna antara pengetahuan, sikap dan keterampilan dalam pengendalian INOS dengan nilai $\operatorname{EXP}(B)=27,500(C l 95 \%: 5,251-144,013)$, $\operatorname{EXP}(B)=15,190(C l$ 95\% : 3,322-69,467) dan EXP $(B)=15,190$ (Cl 95\% : 3,322-69,467. Variabel yang paling dominan yaitu pengetahuan dengan hasil EXP $B=27,500(\mathrm{Cl}$ 95\% : 5,251-144,013).

\section{B. Pembahasan}

1) Hubungan antara pendidikan dengan kinerja perawat dalam pengendalian infeksi nosokomial (INOS)

Hasil penelitian yang diporelah $p$ value $=0,486$ dan $R P=0,542(95 \% \mathrm{Cl}$ 0,126-2,336) yang artinya hubungan antara pendidikan dengan kinerja perawat dalam pengendalian INOS di RSU PKU Bantul Yogyakarta tidak bermakna, atau tidak ada hubungan antara pendidikan dengan kinerja perawat dalam pengendalian INOS di RSU PKU Bantul Yogyakarta. Pada penelitian ini diperoleh nilai $R P=0,542(95 \% \mathrm{Cl} 0,126-2,336)$ menunjukkan bahwa responden dengan tingkat pendidikan rendah berpeluang untuk tidak mengendalikan INOS sebesar 0,542 kali. Tidak ada hubungan yang bermakna secara statistik antara faktor pendidikan dengan kinerja perawat dalam pengendalian INOS atau tidak ada hubungan antara pendidikan dengan kinerja perawat dalam pengendalian INOS. ${ }^{13}$

Pendidikan secara umum adalah segala upaya yang direncanakan untuk mempengaruhi orang lain baik individu, kelompok, atau masyarakat sehingga mereka melakukan apa yang diharapkan oleh pelaku pendidikan. ${ }^{5}$

Unsur-unsur pendidikan yakni input adalah sasaran pendidikan (individu, kelompok, masyarakat) dan pendidik (pelaku pendidikan). Proses adalah upaya yang direncanakan untuk mempengaruhi orang lain. Output yang berarti dalam pendidikan itu terjadi proses pertumbuhan, perkembangan atau perubahan kearah yang lebih dewasa, lebih baik, dan lebih matang pada diri individu, kelompok atau masyarakat. 
2) Hubungan antara pelatihan dengan kinerja perawat dalam pengendalian infeksi nosokomial (INOS)

Hasil penelitian yang diporelah $p$ value $=0,670$ dan $R P=1,432(95 \% \mathrm{Cl}$ $0,512-4,005)$ yang artinya hubungan antara pelatihan dengan kinerja perawat dalam pengendalian INOS di RSU PKU Bantul Yogyakarta tidak bermakna, atau tidak ada hubungan antara pelatihan dengan kinerja perawat dalam pengendalian INOS di RSU PKU Bantul Yogyakarta. Pada penelitian ini diperoleh nilai $R P$ $=1,432(95 \% \mathrm{Cl} 0,512-4,005)$ menunjukkan bahwa perawat yang tidak memiliki pelatihan INOS berpeluang untuk tidak mengendalikan INOS sebesar 1,432 kali. . Ada hubungan yang bermakna secara statistik antara pelatihan dengan kinerja perawat dalam pengendalian INOS. ${ }^{17}$

Pelatihan yang berhubungan dengan kinerja memberikan ruang b a g i pengembangan dan peningkatan keahlian dan kompetensi yang dapat memberikan dampak langsung kepada kinerja individu atau tim. Pelatihan yang relevan dalam arti bahwa pelatihan diarahkan untuk meningkatkan kinerja pada bidangbidang dimana kebutuhan untuk mencapai hasil yang lebih baik telah diidentifikasi secara jelas. Tujuannya adalah untuk mengidentifikasi kebutuhan pelatihan secara individu dan memberikan pelatihan yang relevan dan efektif untuk memenuhinya. ${ }^{6}$

3) Hubungan antara pengetahuan dengan kinerja perawat dalam pengendalian infeksi nosokomial (INOS)

Hasil penelitian yang diporelah $p$ value $=0,000$ dan $R P=7,115(95 \% \mathrm{Cl}$ $2,691-18,812$ ) yang artinya hubungan antara pengetahuan dengan kinerja perawat dalam pengendalian INOS di RSU PKU Bantul Yogyakarta bermakna, atau ada hubungan antara pengetahuan dengan kinerja perawat dalam pengendalian INOS di RSU PKU Bantul Yogyakarta. Pada penelitian ini diperoleh nilai $R P=7,115(95 \% \quad C l$ 2,691-18,812) menunjukkan bahwa responden dengan tingkat pengetahuan rendah berpeluang untuk tidak mengendalikan INOS sebesar 7,115 kali. Ada hubungan yang bermakna secara statistik antara pengetahuan terhadap penerapan SOP teknik menyuntik dalam upaya pencegahan infeksi atau ada hubungan antara pengetahuan terhadap penerapan SOP teknik menyuntik dalam upaya pencegahan infeksi. ${ }^{16}$

Hasil penelitian ini didukung dengan teori Notoatmodjo, (2007) yakni sebelum orang mengadopsi perilaku baru, dalam diri orang tersebut terjadi proses yang berurutan, yakni: a) Awareness (kesadaran), b) interest (merasa tertarik), c) evaluation (menimbang-nimbang), d) Trial (mencoba), e) adoption (adopsi). Apabila penerimaan perilaku baru atau adopsi perilaku melalui proses seperti ini, didasari oleh pengetahuan, kesadaran dan sikap yang positif maka perilaku tersebut akan bersifat langgeng (long lasting), sebaliknya apabila perilaku itu tidak didasari oleh pengetahuan dan kesadaran, maka akan tidak berlangsung lama. 
4) Hubungan antara sikap dengan kinerja perawat dalam pengendalian infeksi nosokomial (INOS)

Hasil penelitian yang diporelah $p$ value value $=0,000$ dan $R P$ $=6,519(95 \%$ Cl 2,088-20,352). yang artinya hubungan antara sikap dengan kinerja perawat dalam pengendalian INOS di RSU PKU Bantul Yogyakarta bermakna, atau ada hubungan antara sikap dengan kinerja perawat dalam pengendalian INOS di RSU PKU Bantul Yogyakarta. Pada penelitian ini diperoleh nilai $R P=6,519(95 \% \mathrm{Cl}$ 2,088-20,352) menunjukkan bahwa responden yang memiliki sikap negatif berpeluang untuk tidak mengendalikan INOS sebesar 6,519 kali. Hasil penelitian ini berbanding terbalik dengan penelitian Idayanti (2008) yaitu tidak ada hubungan yang bermakna secara statistik antara sikap responden dengan penerapan SOP teknik menyuntik dalam upaya pencegahan infeksi, atau dengan kata lain tidak ada hubungan antara sikap responden dengan penerapan SOP teknik menyuntik dalam upaya pencegahan infeksi.

Sikap merupakan semacam kesiapan untuk bereaksi terhadap suatu objek dengan dengan cara-cara tertentu. ${ }^{7}$ Kesiapan dimaksudkan kecendrungan potensial untuk bereaksi dengan cara tertentu apabila individu dihadapkan pada suatu stimulus yang menghendaki adanya respons. Sikap mempunyai tiga komponen pokok, yakni: a) kepercayaan (kenyakinan), ide dan konsep terhadap suatu objek, b) kehidupan emosional atau evaluasi emosional terhadap suatu objek, c) kecendrungan untuk bertindak (trend to behave). Ketiga komponen ini secara bersama-sama membentuk sikap yang utuh. Dalam penentuan sikap, pengetahuan berfikir, kenyakinan dan emosi memegang peranan penting untuk mengambil sikap. ${ }^{10}$

5) Hubungan antara keterampilan dengan kinerja perawat dalam pengendalian infeksi nosokomial

Hasil penelitian yang diporelah $p$ value value $=0,000$ dan $R P=$ 6,519 (95 \% Cl 2,088-20,352) yang artinya hubungan antara keterampilan dengan kinerja perawat dalam pengendalian INOS di RSU PKU Bantul Yogyakarta bermakna, atau ada hubungan antara keterampilan dengan kinerja perawat dalam pengendalian INOS di RSU PKU Bantul Yogyakarta. Pada penelitian ini diperoleh nilai $R P=6,519(95 \% \mathrm{Cl}$ 2,08820,352) menunjukkan bahwa responden yang memiliki keterampilan tidak baik berpeluang untuk tidak mengendalikan INOS sebesar 6,519 kali. Hasil penelitian ini berbanding terbalik dengan penelitian Habni (2009) yaitu keterampilan perawat dalam pengendalian infeksi nosokomial secara keseluruhan memiliki keterampilan sedang.

Perawat yang bertugas memberikan pelayanan kepada masyarakat harus dapat berperilaku professional. Perilaku professional dapat ditunjukkan dan memiliki atau menerapkan keterampilan professional keperawatan serta menggunakan etika keperawatan sebagai tuntunan dalam melaksanakan praktek keperawatan dan kehidupan professional. ${ }^{14}$ 
6) Variabel yang paling dominan pada kinerja perawat dalam pengendalian infeksi nosokomial (INOS)

Dari lima variabel yang diteliti terdapat tiga variabel yang bermakna secara statistic yang memiliki hubungan dengan kinerja perawat dalam pengendalian INOS yaitu variabel pengetahuan, sikap dan keterampilan. Ketiga variabel tersebut dilanjutkan dengan analisis multifariat menggunakan regresi logistik (multiple logistic regression) menunjukkan bahwa variabel yang paling dominan berhubungan dengan kinerja perawat dalam pengendalian INOS adalah variabel pengetahuan. Hal ini menunjukkan dengan nilai signifikansi Sig $<\alpha(0,000<0,05)$ dengan Exp (B) 27,500 yang berarti bahwa secara statistik bermakna.

Ada hubungan yang bermakna secara statistik antara pengetahuan terhadap penerapan SOP teknik menyuntik dalam upaya pencegahan infeksi atau ada hubungan antara pengetahuan terhadap penerapan SOP teknik menyuntik dalam upaya pencegahan infeksi. ${ }^{16}$ Penelitian ini menyebutkan bahwa, semakin banyak responden memperoleh pengetahuan tentang penerapan SOP khusunya teknik menyuntik maka semakin besar responden dapat menjaga kesehatan dan keselamatan dalam bekerja sekaligus mencegah terjadinya infeksi melalui jarum suntik.

Sebelum orang mengadopsi perilaku baru, dalam diri orang tersebut terjadi proses yang berurutan, yakni: a) Awareness (kesadaran), b) interest (merasa tertarik), c) evaluation (menimbang-nimbang), d) Trial (mencoba), e) adoption (adopsi). ${ }^{5}$ Apabila penerimaan perilaku baru atau adopsi perilaku melalui proses seperti ini, didasari oleh pengetahuan, kesadaran dan sikap yang positif maka perilaku tersebut akan bersifat langgeng (long lasting), sebaliknya apabila perilaku itu tidak didasari oleh pengetahuan dan kesadaran, maka akan tidak berlangsung lama.

\section{KESIMPULAN DAN SARAN}

\section{A. Simpulan}

Dari hasil penelitian dan pembahasan mengenai analisis kinerja perawat dalam pengendalian infeksi nosokomial di RSU PKU Muhammadiyah Bantul Yogyakarta, dapat ditarik kesimpulan sebagai berikut:

1. Tidak ada hubungan yang bermakna secara statistik antara pendidikan dengan kinerja perawat dalam pengendalian infeksi nosokomial (INOS) di RSU PKU Muuhammadiyah Bantul Yogyakarta ( $p$ value $=0,486$ dan $R P=0,542(95 \%$ Cl 0,126-2,336).

2. Tidak ada hubungan yang bermakna secara statistik antara pelatihan dengan kinerja perawat dalam pengendalian infeksi nosokomial (INOS) di RSU PKU Muuhammadiyah Bantul Yogyakarta $p$ value $=0,670$ dan $R P=1,432(95$ $\% \mathrm{Cl} 0,512-4,005)$.

3. Ada hubungan yang bermakna secara statistik antara pengetahuan dengan kinerja perawat dalam pengendalian infeksi nosokomial (INOS) di RSU PKU Muuhammadiyah Bantul Yogyakarta $p$ value $=0,000$ dan $R P=7,115(95 \%$ Cl 2,691- 
18,812 .

4. Ada hubungan yang bermakna secara statistik antara sikap dengan kinerja perawat dalam pengendalian infeksi nosokomial (INOS) di RSU PKU Muuhammadiyah Bantul Yogyakarta $p$ value $=0,000$ dan $R P=6,519(95 \%$ Cl 2,08820,352).

5. Ada hubungan yang bermakna secara statistik antara keterampilan dengan kinerja perawat dalam pengendalian infeksi nosokomial (INOS) di RSU PKU Muuhammadiyah Bantul Yogyakarta $p$ value $=0,000$ dan $R P=6,519$ (95 \% Cl 2,08820,352).

\section{B. Saran}

1. Bagi RSU PKU Muhammadiyah Bantul

Upaya untuk meningkatkan tindakan pengendalian dan pencegahan INOS dikalangan tenaga kesehatan, RSU PKU Bantul perlu mengadakan pelatihan secara berkala tentang pengendalian INOS dan menambah sarana dan fasilitas penunjang medik untuk mendukung terlaksananya standar prosedur pencegahan INOS.

2. Praktek keperawatan

Hendaknya tenaga keperawatan aktif mengikuti perkembangan ilmu keperawatan terutama tentang infeksi nosokomial sehingga menambah referensi atau wawasan baru dalam pengendalian Infeksi nosokomial.

3. Bagi Peneliti lain

a. Penelitian lebih lanjut menambah variabel-variabel lain diluar penelitian dan menggunakan metode penelitian yang berbeda.

b. Penelitian lebih lanjut menambah jumlah sampel yang lebih banyak dan menggunakan instrument penelitian yang berbeda.

\section{DAFTAR PUSTAKA}

1. Permenkes RI No 2494/Menkes/Per/XII/2011, Tentang Petunjuk Teknis Penggunaan Dana Alokasi Khusus Bidang Kesehatan Tahun Anggaran 2012, Jakarta.

2. Abdoerrachman, M. Hardjono dkk, Upaya Pengendalian Infeksi Nosokomial di Bagian IImu Kesehatan Anak FKUI/RSCM, Majalah Kedokteran Indonesia volume 48 Nomor 5, Hal. 214. 1998.

3. Departemen Kesehatan RI, 2011, Program Pencegahan Dan Pengendalian Infeksi Nosokomial Merupakan Unsur Patient Safety, Depkes RI, Jakarta: www.depkes.go.id, diakses pada tanggal 21 Maret 2012, Yogyakarta. 
4. Utami, Nur Ratnawati, Pelaksanaan Prosedur Tetap Pencegahan Infeksi Nosokomial Bagi Perawat Pada Neonatal Intensive Care Unit ( NICU) di RSU PKU Muhammadiyah Bantul Yogyakarta, Skripsi, Peminatan Manajemen Rumah Sakit Fakultas Kesehatan Masyarakat Universitas Ahmad Dahlan, Yogyakarta. 2009.

5. Notoatmojo, S, Kesehatan Masyarakat IImu dan Seni, PT Rineka Cipta, Jakarta, Hal.108, 143-144, 146-147. 2007.

6. Dharma, S, Manajemen Kinerja, Pustaka Pelajar, Yogyakarta, Hal. 25, 57, 287-288. 2011.

7. Azwar, S, Sikap Manusia Teori dan Pengukurannya. Pustaka Pelajar, Yogyakarta, Hal 5. 2011.

8. Murti, B, Desain dan Ukuran Sampel untuk Penelitian Kuatitatif dan Kualitatif di Bidang Kesehatan, Gadjah Mada University Press, Yogyakarta, Hal. 53. 2010.

9. Notoatmojo, S, Pendidikan dan IImu Perilaku Kesehatan ,PT Rineka Cipta, Jakarta. Hal.16, 122-124. 2003.

10. Notoatmojo, S, Kesehatan Masyarakat IImu dan Seni, PT Rineka Cipta, Jakarta, Hal.108, 143-144, 146-147. 2007.

11. Notoatmodjo, S, Metodologi Penelitian Kesehatan, Rineka Cipta, Jakarta, Hal, 182, 184. 2010.

12. Notoatmojo, S, Pendidikan dan IImu Perilaku Kesehatan ,PT Rineka Cipta, Jakarta. Hal.16, 122-124. 2003.

13. 13. Bady, A. Marwoto, Analisis Kinerja Sumber Daya Manusia (Perawat) Dalam Pengendalian Infeksi Nosokomial di IRNA I RSUP DR Sardjito Yogyakarta, Tesis, Pasca Sarjana, Universitas Gadjah Mada, Yogyakarta. 2007.

14. 14. Yuliastuti, I, Pengaruh Pengetahuan, Keterampilan Dan Sikap Terhadap Kinerja Perawat Dalam Penatalaksanaan Kasus Flu Burung Di RSUP. H. Adam Malik Medan, Tesis, Pasca Sarjana, Universitas Sumatra Utara, Medan. 2007.

15. 15. Habni, Y, Perilaku Perawat Dalam Pencegahan Infeksi Nosokomial di Ruang Rindu A, Rindu B, ICU, IGD, Rawat Jalan di Rumah Sakit Umum Pusat Haji Aam Malik Medan, Skripsi, Peminatan Keperawatan Fakultas Kedokteran Universitas Sumatra Utara, Medan. 2009.

16. 16. Idayanti, Hubungan Pengetahuan Dan Sikap Perawat Terhadap Penerapan Standar Operasional (SOP) Teknik Menyuntik Dalam Upaya Pencegahan Infeksi Di RSUD Arifin Achmad Pekanbaru, Tesis, Pascasarjana, Fakultas Kesehatan Masyarakat Universitas Sumatra Utara, Medan. 2008.

17. 17. Maryati, S, Keefektifan Peningkatan Kemampuan Perawat Dalam Pencegahan Infeksi Nosokomial Pada Bayi di Ruang Neonatal Intensive care Unit RSUD Wates. 2011. 